This item was submitted to Loughborough's Research Repository by the author.

Items in Figshare are protected by copyright, with all rights reserved, unless otherwise indicated.

\title{
Measurement of underwater noise arising from marine aggregate operations
}

PLEASE CITE THE PUBLISHED VERSION

http://dx.doi.org/10.1007/978-1-4419-7311-5_105

\section{PUBLISHER}

(C) Springer Science+Business Media

\section{VERSION}

AM (Accepted Manuscript)

\section{LICENCE}

CC BY-NC-ND 4.0

\section{REPOSITORY RECORD}

Lepper, Paul A., Stephen P. Robinson, Pete D. Theobald, Lian-Sheng Wang, Gary Hayman, and Samantha Mumford. 2019. "Measurement of Underwater Noise Arising from Marine Aggregate Operations". figshare. https://hdl.handle.net/2134/9517. 
This item was submitted to Loughborough's Institutional Repository (https://dspace.lboro.ac.uk/) by the author and is made available under the following Creative Commons Licence conditions.

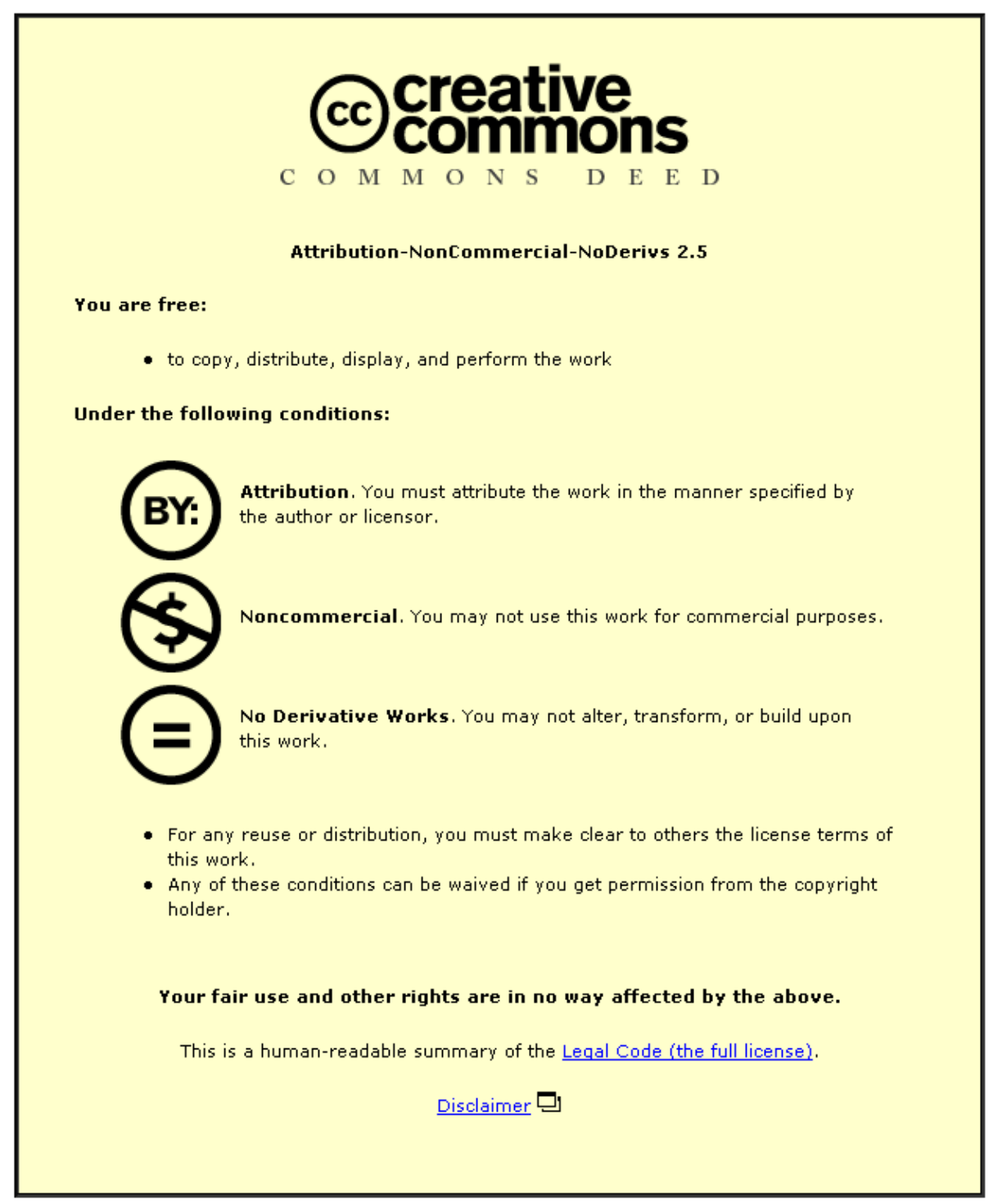

For the full text of this licence, please go to: http://creativecommons.org/licenses/by-nc-nd/2.5/ 


\section{Measurement of underwater noise arising from marine aggregate operations}

S. P. Robinson ${ }^{1}$, P. D Theobald ${ }^{1}$, P.A. Lepper ${ }^{2}$, G. Hayman ${ }^{1}$, V. F. Humphrey ${ }^{3}$, L-S. Wang ${ }^{3}$, S. Mumford ${ }^{4}$.

${ }^{1}$ National Physical Laboratory, Teddington, UK, stephen.robinson@npl.co.uk

${ }^{2}$ Loughborough University, Leicestershire, U K, p.a.lepper@lboro.ac.uk

${ }^{3}$ Institute of Sound and Vibration, University of Southampton, U K, vh@,isvr.soton.ac.uk

${ }^{4}$ Gardline Environmental, Great Yarmouth, UK, samantha.mumford@gardline.com

\section{Introduction}

As of 2009 there were 75 licensed areas within UK waters for marine aggregate extraction, with dredging activity taking place at any given point in time. In 2008, the dredged area totalled $137.9 \mathrm{~km}^{2}$, extracting 21.24 millions tonnes of sand and gravel for the building and construction industry. There is concern that the extraction of marine aggregate has the potential to generate noise levels which could have a negative impact on marine species in or around the dredging area. There are many ways in which dredging can have an impact on marine life, although this paper deals only with the underwater noise generated and the potential impact it might have. For marine aggregate extraction, the type of dredger used is a trailing suction hopper dredger (TSHD). This type of dredger lowers a drag head and suction pipe to the sea floor, in water depths of up to $50 \mathrm{~m}$, to extract the sand or gravel, depositing it in a hopper on the vessel. The vessel will often screen the dredged material for granular size and return the unwanted material and water over the side of the vessel. Such an operation can taken anything from as little as 3 hours to anything up to 12 hours, concentrated to a relatively small area. The vessels usually dredge in tight lanes, usually less than $2 \mathrm{~km}$ in length and up to $100 \mathrm{~m}$ in width.

There has been very little work in the UK on assessing the noise generated by marine aggregate extraction operations and its potential impact on aquatic life. The most extensive measurements of dredging activity was undertaken in the Beaufort Sea during oil exploration activities in the 1980's, which 
included a number of examples of suction dredgers which are summarised in publications by Greene (1987) and Richardson et al. (1995). Although mostly lower frequency measurements and not strictly comparable with dredger used in the UK for marine aggregate extraction, the measurements did indicate that suction dredging activities can generate similar source levels to those of larger tanker vessel when underway. Other measurements around Sakhalin Island, which were compared by Ainslie et al. (2009) to other vessels including the Overseas Harriette measured by Arveson and Vendittis (2000), do support this finding that dredgers whilst extracting aggregate, generate noise levels in the lower frequency region similar to those of larger tanker or cargo carriers whilst underway, as do other measurements in the UK which are not reported in the open literature.

This paper reports some initial results from measurements of one of the largest trailing suction hopper dredger vessels in the UK fleet, the Sand Falcon, and considers the noise it generates under different operating conditions.

\section{Generation of noise from trailing suction hopper dredgers}

The potential sound sources during a dredging activity are numerous and their relative contributions to the overall noise generally are mostly unknown. Due to the suction pipe, drag head, and the return of high volumes of excess water from the vessels hopper over the sides from both spillways and screening towers, the noise generated by this type of vessel is very different from that of conventional ship noise. Even though their transit speed is very slow whilst dredging, typically less than 1.5 knots, they have been shown to generate third-octave source levels at lower frequencies that are comparable to larger tankers and cargo vessels whilst underway at speed Ainslie et al. (2009) and Richardson et al. (1995).

The possible source mechanisms for a TSHD vessel whilst dredging will be propeller/thruster noise (very low speed), general hull radiated hull noise (this could include internal pumps), drag head noise, overboard pump noise, suction pipe noise and water and sediment discharge noise. The first two of these are common to other surface vessels, possibly with the exclusion of the large internal pumps on some vessels, but the other are unique to this type of dredging vessel and could radiate sound into water at 
higher frequencies than those normally associated with surface vessels. The water and sediment discharge has the potential to generate bubbles in the water and therefore broadband noise. The suction pipe and overboard pump also have the potential to generate broadband noise through friction and cavitation respectively. The effect of the drag head is more difficult to postulate but it is possible that it could generate some vibration in the seabed.

\section{Measurement methodology}

In order to measure the noise generated from the dredging vessel, a series of static measurement locations were used whilst the dredger passed by dredging with screening, pumping only water (drag head lifted), and dragging its drag head whilst not pumping (pumps off).

The static measurement locations were provided by noise monitoring buoys, designed and manufactured by Loughborough University, UK, positioned at around 20-40 m and $500 \mathrm{~m}$, and by a survey vessel positioned around $100 \mathrm{~m}$ off the dredging lane. The buoys were aligned to form a normal intersect with the dredging lane, whilst the measurement vessel was set off this transect slightly. Both the buoys and the measurement vessel were positioned to measure the dredger along the centre portion of its dredging lane length, which was around $1 \mathrm{~km}$ in length. The positions of the buoys and measurement vessel were marked with GPS whilst the complete track for the dredging vessel, the Sand Falcon was provided by the vessel operators, Cemex UK, for the entire duration of dredging.

The survey vessel was used to deploy a broadband acoustic measurement system and a CTD to determine the sound speed profile. The acoustic measurement system deployed from the survey vessel consisted of two Reson TC4032 low noise hydrophones on a weighted line with an integral bungee cord length, sub-surface resistor and surface float arrangement to reduce the low frequency influence of wave motion. The water depth was approximately $30 \mathrm{~m}$ and the hydrophones were each at a depth of around $6.5 \mathrm{~m}$ and $10 \mathrm{~m}$. The hydrophones were attached to a B\&K Pulse system and sampled with a 24-bit resolution at a sample rate of $200 \mathrm{kHz}$ on each channel, providing a measurement bandwidth of $100 \mathrm{kHz}$. The hydrophones were deployed throughout the measurement period for around 6 hours whilst the survey 
vessel was anchored and silent. The tidal flow peaked at around 3 knots during the measurements and although some of the measurements were performed over a slack tide, local conditions resulted in relatively high flow conditions even around the slack tide. The sea-state was relatively flat during the measurements at around Force 2. The water temperature was measured to be approximately $4.6^{\circ} \mathrm{C}$ and showed negligible changed over a depth of $20 \mathrm{~m}$.

\section{Results and Discussion}

The data gathered were extensive and so only a small sample of the data is presented here. Given that full analyse has not been completed at this stage in the project, only the third octave-band receive levels at the measurement locations are presented. To assess the characteristics of the noise generated by the dredging activity, the receive levels are shown (see Fig. 1) for the different operational conditions of the Sand Falcon. These are full dredging (sucking sand and gravel from the seabed), pumping only water (with drag head lifted but all pumps still running), no pumping but still dragging (pumps off with the drag head on the seabed). Background noise measurements were also performed on the following day once the Sand Falcon has left the area and these are also included in Fig. 1.

The results shown in Fig. 1 are for when the Sand Falcon was at its position of closest approach to the survey vessel and are taken using a 4 second spectral average over approximately 90 seconds of data in each case, except for the background noise which was from 7 minutes of measurement data. This was measured from the survey vessel using the shallower of the two Reson TC4032 hydrophones. The data clearly shows difference in the higher frequency noise levels (above $1 \mathrm{kHz}$ ) with full dredging approaching level that are $20 \mathrm{~dB}$ higher above $16 \mathrm{kHz}$ when compared with pumping water only or

dragging the drag head with no pumping. Although this has not been fully analysed, this does indicate that it is the effect of the sand and gravel passing through the suction pipe and pump that generates much of the higher frequency noise. It should be noted that dragging the drag head with no pumping is not an 
actual operational state for dredging activities and was done as part of this exercise to help identify the different source which contribute to the spectra.

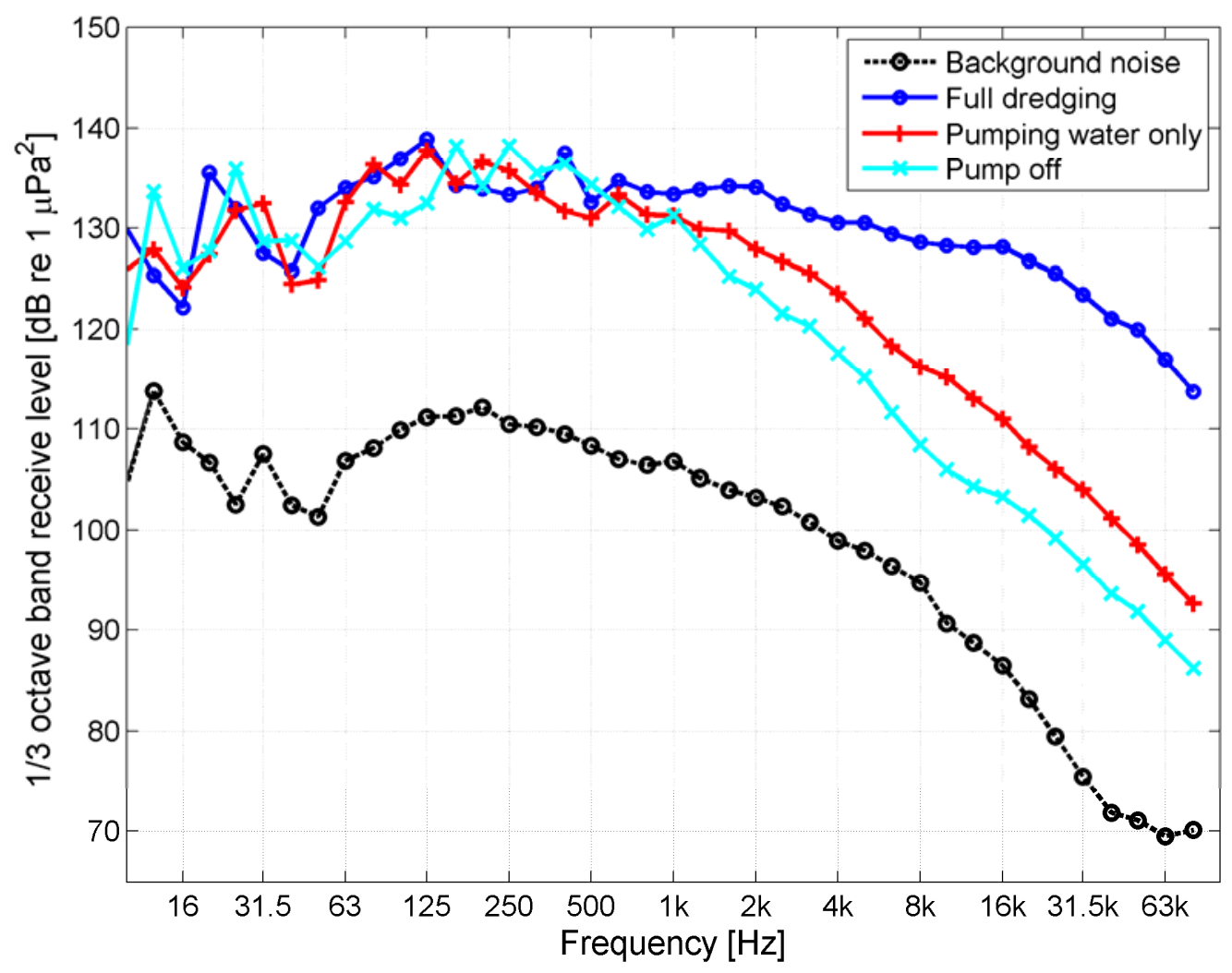

Fig. 1. Third octave-band spectra for the Sand Falcon full dredging, pumping only water (drag head lifted), drag head on seabed with pump off and background noise, measured at approximately $100 \mathrm{~m}$.

To assess the impact of the noise generated from marine aggregate extraction operations, it is necessary to analyse the existing data to calculate the third octave source level data and then use this, with detailed knowledge of the transmission loss in the area, to estimate the zones of potential impact on different marine species. The work reported here are just the initial results from the first part of such a study. 


\section{Conclusions}

A comprehensive set of acoustic measurements have been completed of the underwater noise radiated from a large trailing suction hopper dredger in shallow UK coastal waters whilst extracting sand and gravel from the seabed. Initial analysis of the receive level data in third octave-bands shows significant variation between operational dredger conditions at higher frequencies, which also indicates that the dominant noise source at frequencies above $2 \mathrm{kHz}$ might be caused by the sand and gravel passing through the suction pipe and pump. The peak levels however do occur below $500 \mathrm{~Hz}$ and are consistent with ship noise and hull noise.

\section{Acknowledgements}

The authors would like to acknowledge the financial support of the Marine Aggregate Levy Sustainability Fund, administered by the Marine Environmental Protection Fund and would further like to acknowledge the support and cooperation of the British Marine Aggregate Producers Association and Cemex UK.

(C) Queen's Copyright Printer and Controller of HMSO, 2010

\section{References}

Ainslie MA, de Jong CAF, Dol HS, Blacquière G, and Marasini C (2009) Assessment of natural and anthropogenic sound sources and acoustic propagation in the North Sea, TNO Report TNODV 2009 C085.

Arveson PT and Vendittis DJ (2000) Radiated noise characteristics of a modern cargo ship. J. Acoust. Soc. Am., 107, $118-129$.

Greene CR (1987) Characteristics of oil industry dredge and drilling sounds in Beaufort Sea, Journal of the Acoustical Society of America, 82, (4), 1315-1324. 
Richardson WJ, Greene CRJ, Malme CI and Thomson DD (1995) Marine mammals and noise.

San Diego: Academic Press. 


\section{FIGURE LEGENDS}

Fig. 1. Third octave-band spectra for the Sand Falcon full dredging, pumping only water, drag head on seabed with no pumping and background noise, measured at approximately $100 \mathrm{~m}$. 